\title{
TRANSLATING CRAFT TRADITIONS: PROBLEMS OF TERMINOLOGY IN LATVIAN TRADITIONAL KNITTING BOOKS
}

\author{
Baiba Egle ${ }^{1}$
}

\begin{abstract}
Language for special purposes is in every aspect of life, even our cultural traditions and crafts. Often, cultural terms seem self-explanatory to the people within the source text culture, in this case, Latvians, and might be unknown to other cultures. There is often a goal to achieve perfect equivalency in translation, so there should be a translation for every term. However, it is not always possible to transfer the meaning of a concept that has both technical and cultural aspects. The translator has to look at both the source and the target culture's knowledge to adapt the translation as needed.

This paper will look at the terminological problems encountered within the English translations of two books that look at Latvian traditional knitting - Suiti patterned socks and south Kurzeme jackets. While it might seem like these books describe simple items, there is a lot of special terminology used therein. Through a selection of translation problems found in these sources, the cause of the mistakes is explored and the suggestions of the correct variant are given. The results of the research show that while specific cultural terms can be hard to translate, there are strategies to translate even the most complex culturebound terms correctly and what skills and background knowledge are needed for it.
\end{abstract}

UDC Classification: 811.174 , DOI: https://doi.org/10.12955/pss.v1.43

Keywords: Latvian, English, translation, knitting, specialized language

\section{Introduction}

Knitting is part of the culture in many countries worldwide. This tradition has endured centuries, passed down from one knitter to another. Nowadays, knitting is a popular hobby once again, as people are not only knitting things that are traditional for their location or cultural background and there is a rising interest in various traditions from around the world. While many international knitters might recognize Fair Isle and Orenburg lace as a certain style of knitting, until recently, not much about Latvian knitting has been published in English.

Knitting is a craft that relies on text to ensure the knowledge transfer. While historically Latvian knitting traditions were given to the next generation in spoken words and demonstrations of how to practically do a certain technique, nowadays authors strive to preserve these in textual form for Latvians and a broader audience. This broader audience is targeted via the translation of the Latvian original text into English, as English is likely to have a larger audience who could be interested in a specific knitting text.

While it may seem that a knitting text is just a straightforward manual that should be accessible to any reader, it has far more complex implications than other technical texts, especially when it comes to regional specifics of knitting that can require a larger amount of explanation than standard basic terms known to any reader of the text. When this text is translated, then it adds another level of complexity to the translation and the skills and experience needed for a successful translation that stays true to the source material and does not confuse the target text reader.

Hann (1992, p.7) writes that "technical translation is essentially a decision-making process involving selection of the correct target-language rendering from a number of different, context-dependent alternatives". For knitting text, the context-dependent target would be the equivalent knitting term if it exists in English or an attempt of creating such if it is not yet used, for terms that describe specifically Latvian knitting techniques.

In this article the author will look at two books that focus on traditional Latvian knitting - two distinct knitting styles from the Kurzeme Region. These are the publications by the Latvian National Culture Centre whose aim is to nurture and preserve culture and traditions. The books include both Latvian and English text side by side, within each volume, so the source text (in Latvian) and target text (English) are available for direct comparison and analysis. The inclusion of both languages allows a broader readership to access the information. It should be noted that the books chosen for analysis in this paper represent ethnographic traditions and are based on museum item research are not a contemporary variation on Latvian knitting like the recent original English language works (Ozolina 2018; Ozolina 2019) that still make use of traditional techniques. However, the main source of knowledge about traditional knitting in Latvia often is either learning directly from someone who knows how to knit a

\footnotetext{
${ }^{1}$ Ventspils University of Applied Sciences, Department of Translation Studies, Ventspils, Latvia. baiba.egle@venta.1v
} 
certain thing or from ethnographically focused texts, like those discussed in this paper. These more modern approaches to traditional Latvian knitting might cause more interest about other sources related to this topic and thus more Latvian works about knitting could be translated into English and should be, but in translations that are both technically and culturally correct.

Cronin (2010) suggests that translation could be a way to expand possibilities in the age of globalization and share the perspective of micro-modernity to show a local perspective. The translation of culturally relevant materials is thus not a way to adapt the Latvian tradition to the global tradition,but rather to show our perspective.

Can one transfer culture through a technical text? Can a technical text be adapted to a target language culture to be more comprehensible? Not all technical texts will be tied to a specific culture, for example, a manual for software would not include information that has shaped a culture, and knitting is done not only in Latvia, but also in many other countries around the world. In each of these long-standing kniting cultures, an array of special terms and tacit and explicit knowledge has been developed. The translator's job, therefore, is a balancing act between the source text culture and the target text culture, conveying the content of the text in line with its pragmatic goal. The author of the paper agrees with Yan and Huang (2014) in that a translator should use the cultural approach along with the linguistic approach to convey the message of the text.

\section{Analysed material and translation issues}

The material chosen for the analysis was selected based on the following criteria: 1) does it represent a specific aspect of Latvian knitting culture; 2) has it been published relatively recently, that is, no less than five years ago; 3 ) does the text contain both the original source text and an English translation.

The first aspect of whether the material represents culture significantly is important as a general publication about non-specific items might not use culturally bound terms, thus these would pose significantly less possibility of causing translation problems. Secondly, recent publications show the current situation in publishing and give insight into books that could reach an international reader, unlike older publications that might only exist in few copies and are not available to purchase anymore. Thirdly, if the original source contains both the original and translation it could be assumed that the author and publisher have approved the translation and it could be deemed an official translation of the work. A published book typically goes through various stages of approval and editing, and the translation would have been done by a professional and not by an amateur translator who just wanted to share some of their knowledge.

Two recent publications have met these aforementioned criteria, and each is described separately as the terminology used in each is different and translation issues arising are based on the source text.

\section{Translation problems in the technical description of South Kurzeme Jackets}

South Kurzeme Knitted Jackets by Linda Rubena was published in 2018 and is the first comprehensive work about the hand knit jackets of the region in written form. Rubena (2018) mentions on the cover of the book that it has information of descriptions drawings and techniques used in knitting the jackets and that the information compiled in the book may become an inspiration to knit one's own jacket. However, the book is not a manual of instruction, where the reader would expect to be given extensive instructions on how to complete such a garment. It is rather a scientific and ethnographic review, that first gives insight into the existing ethnographic research within the topic. This paper will take a closer look at the more technical aspects of the knitting process descriptions which is crucial for text comprehension to ensure that the reader could be inspired as Rubena hopes.

The following examples are a small selection chosen to give insight into the terminological issues that can be encountered when translating a niche, specific technical text. It calls for precision in translation as the terms need to be rendered from Latvian into English with the correct term or suitable explanation if a new term in English needs to be created.

Some translation issues, like describing home spun yarn (mājās vērptas dzijas) as yarns twisted at home could be ignored in this case as it is not a significant mistake. Verrpt is spinning, not just twisting a yarn, a small practical difference. This translation might give an English- speaking knitter the impression that Latvians did not spin yarn at home, but only twisted or plied pre-made yarn which can be done as well. 
The author of this paper has spoken to knitters from the South Kurzeme region who have created several traditional jackets and these informal, unstructured interviews concluded that the biggest issue they see in this book is that the technical description is partly incorrect as the information compiled in Rubena's book is based on a variety of ethnographic research, but lack the tacit knowledge needed to create these jackets that the south Kurzeme knitters have. As Davies (2001) states, implicit knowledge is simply knowledge that is not explicit and where the knower of such information might have trouble giving a verbal account. Therefore, writing down such information poses difficulty in the source language and makes translation more complicated. An aspect of tacit knowledge that is needed to understand this text is that the jackets are knit flat, that is, knit with rows going back and forth and not joined in the round to form a tubular construction. This creates the problem of mistranslation regarding the brioche stitch description, calling rows forward and backward which may visually represent rows when working the knitting, but is not terminologically correct in English, as the generally accepted terms are right side (front of the work) and wrong side (the back of the work). The description of the honeycomb brioche stitch then continues with incorrect terminology, as it instructs to begin from the left side which is a direct word by word translation from Latvian sāk no kriesās puses. The correct instruction would be begin from the wrong side of the work as it would fit the typical knitting terminology used in English and not create confusion as the technical descriptions are brief therefore every word should be unmistakably correct. There are also knitting charts, that is, a visual representation of knitting stitches via symbols is used to create the pattern. Unfortunately, the chart is not easily read in English, as one of the stitches is described as a shawled stitch which is a term that might have been introduced by the translator as such a term does not exist in English and searching online would not help a reader to understand this term better as it is an introduced term found nowhere else. The correct description of it is a slipped stitch with a yarn over that describes the action sequence needed.

\section{Translation problems in Suiti Patterned Socks}

The second book chosen for analysis in this paper is Lia Mona Ģibiete's Suiti Patterned Socks published in 2017. It describes the knitting tradition of the Kurzeme region Suiti people and focuses on their traditional sock knitting. Giibiete $(2017,5)$ writes that "ethnographic knits with their distinct colour and pattern combination have proven themselves to be a stable core value despite changing fashion trends, materials, abilities, knitting methods and techniques". Stable core values of a culture can be interesting to a broad range of readers, so it is important to share them and teach others more about them.

The first translation issue is already in the title of the book, as anything can be a pattern, including, colour or shape, but it is not quite the correct translation as the Latvian rakstainās refers to the fact that these socks are knit using several yarn colours to create a certain pattern. Colourwork would be a better choice as this would emphasize the technique and specific type of hand knit. Colourwork is a technique where the knitter uses different colours at once. It is a complex technique and requires knitting experience and background knowledge to recreate any visual chart of the colorwork. A chart consists of colour squares that represent one stitch each. The book describes the history and traditions of the Suiti sock, however, similar to the Rubene's book on south Kurzeme, Jackets, Gibiete's work is also not an instruction manual. It delves into the history of the tradition and has plentiful illustrations, however, once again, this technique requires a significant amount of tacit knowledge and experience to recreate the socks shown in illustrations.

One might assume that if a text relies on visual material, such as photographs and charts, then there is a lesser risk of translation mistakes happening. Unfortunately, some errors have occurred in the English translation of terms relating to the arrangement of colorwork in the socks.

The first group of Suiti colourwork patterns is described as unconnected knitting patterns which might not seem immediately understandable looking at the photographs of such socks. These are described as socks that do not have a diagonal or other type of line connecting separate pattern elements, however, these patterns are mostly known in Latvian as pukites or rozites, that is, flowers or roses. Naming this category after its closest visual representation would have been closer to the source text culture and might not seem too foreign to an English translation reader as well, as general flower shapes could be recognized no matter which culture the potential source text reader is from.

The next category of pattern groups is knotty mesh patterns (zaraino režǵ $u$ ) These are supposed to designate patterns that are linked together via diagonal lines that form a diamond shape with the center 
part of the diamonds as the main focus of the pattern. There are no knots in it, it is a symmetrical pattern that is interlinked. The biggest issue is the English translation of the Latvian term režgis that describes a grid of some sort, but the translator's choice of mesh can give a false impression. Usually, in textiles, a mesh is a light, see through fabric with holes. As the Suiti socks are knit in the colorwork technique, they do not have holes, the knit fabric is dense because of the many, coloured yarn strands used in the work. The next pattern group name is translated as the different mesh (dažâdu režǵ $u$ ) patterns. This does not fully describe the difference of this group from the one previously mentioned as this category focuses on the complexity of the diagonal lines that form the diamond in the pattern, not the center of the shape. So perhaps a more matter of fact translation, such as intricate line diamond might have been more selfexplanatory.

While these two pattern group name translations could be still understood by the target text reader after looking at the visual material provided in the book, the fourth name of the pattern groups has been incorrectly translated, even though it is the simplest one to implement in knitting.

Joslu raksti designate a group of patterns that can be classed as variations of a simple colour stripe pattern. The translator chose to translate this as border and crochet patterns which is not only incorrect but uses two terms that are not suitable to describe it. First of all, in typical English knitting terminology, socks do not have a border, but one can create as many stripes as one wants. Crochet is a craft that uses a single hook to create a fabric and there is no crochet involved the creation of the Suiti sock. What the translation should have been is stripe and chevron patterns as the concept of what a chevron pattern looks likely familiar to the potential target text readers in English.

\section{Conclusion}

This brief analysis shows that the translations of Latvian knitting texts have a variety of problems. While this paper gives just a brief overview of the issues encountered, it found that even simple concepts that could have been understood better if the translator had had a broader knowledge of the knitting terminology used in English and used the visual material in the source text as an aid to the translation process to ensure that all information is rendered as correctly as possible. As Risku (2004, p. 193) notes, "a lack of specific knowledge, skills, experiences and characteristics that are equally important for both TC [technical communication] and translation". The translation problems discussed in this paper are likely not a sign of a translator being lazy and careless with their work, it might have been a lack of skills and experience within the knitting realm. Ideally, such specific texts should be translated by a translator who has experience not only in translation, but also in knitting and the English-speaking knitting culture and terminology. This is of course an idealistic scenario but in theory it could be possible that a translator with good research skills and reasoning could be able to translate such specific text.

If at some point in the future these two discussed books are given a second print run, hopefully these mistakes could be corrected. Translation problems have always existed, and the examples discussed in this paper show that when culture and technical aspects are combined in a text they are inevitable. This could be reason for further research into other technical and culturally specific texts in other languages and cultures.

\section{References}

Cronin, M. (2010). The Expanding World: Translation, Mobility and Global Futures. In Baker, M., Olohan, M., Pérez Calzada, M. (Eds.), Text and Context: Essays on Translation and Interpreting in Honor of Ian Mason.(pp.303-318) London: Routledge

Davies, M. (2001). Knowledge (Explicit and Implicit): Philosophical Aspects. International Encyclopedia of the Social \& Behavioral Sciences, 8126-8132. doi:10.1016/b0-08-043076-7/00995-5

Ģibiete, L. (2017). Suiti Patterned Socks. Rīga: Latvijas Nacionālais kultūras centrs

Hann, M. (1992). The Key to Technical Translation. Amsterdam: John Benjamins

Olohan, M. (2015). Scientific and Technical Translation . London: Routledge

Ozolina, I. (2018). Knit like a Latvian. Pynes Hill: Sewandso

Ozolina, I. (2019). Knit Like a Latvian... Socks. Exeter: David and Charles

Risku, H. (2004). Migrating from translation to technical communication and usability. BENJAMINS TRANSLATION LIBRARY, 50, 181-196

Rubena, L. (2018). South Kurzeme Knitted Jackets. Rīga: Latvijas Nacionālais kultūras centrs

Yan, C., Huang, J. (2014) The Culture Turn in Translation Studies. Open Journal of Modern Linguistics, 4, 487-494. doi: 10.4236/ojml.2014.44041 